\title{
ADAPTAÇÃO ENZIMÁTICA DA LDH EM RATOS SUBMETIDOS A TREINAMENTO AERÓBIO EM ESTEIRA E LASER DE BAIXA INTENSIDADE
}

\author{
Vieira WhB ${ }^{1}$, Goes R ${ }^{1}$, Costa FC ${ }^{1}$, Parizotto NA ${ }^{1}$, Perez SEA ${ }^{2}$, Baldissera V ${ }^{2}$, Munin FS ${ }^{3}$, \\ SCHWANTES MLB ${ }^{3}$ \\ ${ }^{1}$ Laboratório de Eletrotermofototerapia, Departamento de Fisioterapia, Universidade Federal de São Carlos - UFSCar, \\ São Carlos, SP \\ ${ }^{2}$ Laboratório de Fisiologia do Exercício, Departamento de Ciências Fisiológicas, UFSCar, São Carlos, São Carlos, SP \\ ${ }^{3}$ Laboratório de Evolução Molecular, Departamento de Genética e Evolução, UFSCar, São Carlos, SP \\ Endereço para correspondência: Nivaldo Antonio Parizotto, Lab. de Eletrotermofototerapia, DeFisio, UFSCar, Via \\ Washington Luís, Km 235, CP 676, CEP 13565-905, São Carlos, SP, e-mail: parizoto@power.ufscar.br
}

Recebido: 12/04/2005 - Aceito: 09/03/2006

\begin{abstract}
RESUMO
Objetivo: Verificar a atividade e padrão eletroforético da LDH em resposta ao exercício em esteira em ratos submetidos à fotoestimulação por laser de baixa intensidade (780 ๆm). Método: Foram utilizados nesse estudo 54 ratos machos jovens (30dias), Winstar, com peso inicial médio de $112 \pm 4,7 \mathrm{~g}$, os quais foram divididos em quatro grupos: dois permaneceram em repouso, GRC (grupo repouso controle, $\mathrm{n}=9$ ) e GRL (grupo repouso laser, $\mathrm{n}=10$ ), sendo o segundo irradiado por laser, e outros dois foram submetidos ao treinamento aeróbio e testes de esforço crescente em esteira (em degraus descontínuos) visando à determinação do limiar de anaerobiose (LA) durante 5 semanas, GEC (grupo exercício controle, n=16) e GEL (grupo exercício laser, $n=19$ ), sendo o último também irradiado por laser. O laser foi aplicado no quadríceps, glúteo máximo, sóleo e tibial anterior (TA), bilateralmente, imediatamente após cada sessão de treinamento, usando: $3,8 \mathrm{~J} / \mathrm{cm}^{2}, 15 \mathrm{~mW}, 10 \mathrm{~s}$, modo contínuo, durante 5 semanas. Amostras de sóleo, TA e coração foram removidas 48 horas após a última sessão de exercício para análise eletroforética e espectrofotométrica. A estatística foi realizada através do teste ANOVA e post-hoc de TUKEY. O nível de significância foi considerado ( $\mathrm{p} \leq$ 0,05). Resultados: Foram observadas reduções na atividade da LDH causadas pelo laser (de 19\% a 30\%), exercício (de 41\% a 66\%) e as ações combinadas (de 47\% a 66\%) ( $\mathrm{p}<0,01$ ). A eletroforese mostrou uma predominância da subunidade B para o sóleo e coração, e uma predominância da subunidade A no TA. Conclusões: Estes dados sugerem uma melhor resposta adaptativa dos animais ao treinamento aeróbio associado à terapia laser, no que se refere à otimização da via oxidativa.
\end{abstract}

Palavras-chave: LDH, Eletroforese, treinamento de endurance, rato, LLLT.

\section{ABSTRACT \\ Adaptation of LDH Enzyme in Rats Undergoing Aerobic Treadmill Training and Low Intensity Laser Therapy}

Objective: To analyze the activity and electrophoretic pattern of the enzyme LDH in response to treadmill training, in rats undergoing photostimulation using low-level laser therapy (LLLT) (780 $\eta \mathrm{m})$. Method: Fifty-four 30-day-old male Winstar rats initially weighing $112 \pm 4.7 \mathrm{~g}$ were divided into four groups. Two groups remained at rest: resting control group (RCG, $\mathrm{n}=9$ ) and resting LLLT group ( $R L G, n=10)$. The other two groups underwent a five-week treadmill program of aerobic training and noncontinuous incremental effort tests, with the aim of determining the anaerobic limit. One of the latter was an exercise control group (ECG, $n=16$ ) and the other was an exercise LLLT group (ELG, $n=19)$. LLLT was applied to the quadriceps, gluteus maximus, soleus and tibialis anterior, bilaterally, immediately after each training session, using the following: $3.8 \mathrm{~J} / \mathrm{cm}^{2} ; 15 \mathrm{~mW}$; time 10 $\mathrm{s}$; continuous mode. Samples of the soleus, tibialis anterior and heart were removed 48 hours after the last exercise session for electrophoretic and spectrophotometric analysis. The statistical analyses used were the ANOVA and post-hoc Tukey tests. The level of statistical significance was set at $\mathrm{p} \leq 0.05$. Results: Reductions in LDH activity caused by laser (from 19\% to 30\%), exercise (from $41 \%$ to $66 \%$ ) and combined action (from $47 \%$ to $66 \%$ ) were observed $(\mathrm{p}<0.01)$. Electrophoresis showed predominance of subunit B in the soleus and heart, and predominance of subunit A in the tibialis anterior. Conclusion: The data suggest that the animals have an adaptive response to aerobic training with LLLT, towards optimizing the oxidative pathway.

Key words: LDH, Electrophoresis, endurance training, rat, LLLT. 


\section{INTRODUÇÃO}

A terapia laser de baixa intensidade (LLLT) é um recurso fisioterapêutico que possui propriedades especiais capaz de produzir efeitos bioquímicos e fisiológicos nos tecidos ${ }^{1}$. Dentre os efeitos pode-se destacar os relacionados com a bioenergética, como o aumento na taxa energética e síntese de ATP mediante modificações mitocondriais ${ }^{2-10}$.

Alguns estudos sugerem que em células irradiadas, os primeiros eventos fotoquímicos e fotofísicos acontecem nas mitocôndrias, cujas alterações respiratórias são explicadas como resultado tanto de mudanças estruturais ${ }^{9,10}$ quanto de alterações químicas (metabólicas) nessa organela citoplasmática, podendo ocorrer no potencial de membrana ${ }^{5,6} \mathrm{e} / \mathrm{ou}$ em atividades enzimáticas ${ }^{4,7,11,12}$, todas contribuindo para a maior disponibilidade de energia, via metabolismo aeróbio, para ser utilizada na realização das atividades celulares.

No que se refere à atividade enzimática, tem-se que a mensuração desta nas fibras musculares fornece uma indicação relativa de seu potencial de oxidação, tendo em vista que um grande número de enzimas é necessário na oxidação de nutrientes energéticos. O sistema isozímico da lactato desidrogenase (LDH - enzima terminal da glicólise anaeróbia) se constitui no mais estudado na maioria dos vertebrados, pois é considerado um dos melhores meios para estudos de ajustes metabólicos (aspectos adaptativos) a variações nos parâmetros externos ou internos das espécies ${ }^{13}$. Essa enzima aparece no tecido das espécies em, geralmente, cinco formas isozímicas/isofórmicas separáveis por eletroforese, as quais são resultantes da associação, ao acaso, de duas subunidades distintas: $\mathrm{A}$ (ou M) e B (ou H), que apresentam características estruturais e funcionais próprias e são codificadas por dois loci diferentes. A associação dessas duas subunidades permite a ocorrência de, pelo menos, duas isoformas homotetraméricas: a $\mathrm{A}_{4}\left(\mathrm{M}_{4}\right)$ ou $\mathrm{LDH}_{5}$ típica de musculoesquelético predominantemente anaeróbio, e $\mathrm{B}_{4}\left(\mathrm{H}_{4}\right)$ ou $\mathrm{LDH}_{1}$, típica de músculo cardíaco, tecido predominantemente aeróbio, bem como, três isoformas heterotetraméricas, $\mathrm{A}_{3} \mathrm{~B}\left(\mathrm{LDH}_{4}\right), \mathrm{A}_{2} \mathrm{~B}_{2}\left(\mathrm{LDH}_{3}\right), \mathrm{AB}_{3}$ $\left(\mathrm{LDH}_{2}\right)^{14}$. A isoforma $\mathrm{A}_{4}$ é considerada uma piruvato redutase, atuando, pois, na manutenção do balanço redox durante períodos de escassez de $\mathrm{O}_{2}$, sendo encontrada em tecidos com alto potencial glicolítico. Por outro lado, a isozima $\mathrm{B}_{4}$ é considerada como lactato oxidase, e assim, "desvia" o substrato para o metabolismo aeróbio, evitando que o coração acumule lactato, sendo encontrada em tecidos com metabolismo, predominantemente aeróbio. Uma relação B/A (atividade enzimática em baixa concentração / atividade enzimática em alta concentração de substrato) pode fornecer uma idéia do tipo de subunidade predominante em cada tecido.

Além dos efeitos do laser sobre o metabolismo energético, em destaque a atividade de enzimas chaves de rotas metabólicas, sugere-se que o treinamento físico aeróbio também promova mudanças nas características estruturais e metabólicas do tecido muscular, favorecendo o uso da via aeróbia em detrimento da anaeróbia durante o exercício ${ }^{15,16}$.

Assim, a LLLT pode ser uma coadjuvante do exercício para o aumento da capacidade aeróbia de indivíduos, tendo em vista que alguns de seus achados sobre a bioenergética das células musculares se assemelham a algumas das adaptações musculares ao treinamento físico, em especial o de endurance. No entanto, não há relatos na literatura científica de estudos in vivo, devidamente controlados investigando o efeito conjunto do laser e atividade física sobre a performance aeróbia, especificamente as respostas adaptativas do sistema isozímica da $\mathrm{LDH}$, tendo em vista que essa é uma área de pesquisa inovadora, e, portanto, ainda pouco explorada. Portanto, o objetivo desse estudo foi verificar possíveis adaptações bioquímicas referentes, a atividade enzimática e padrão eletroforético da LDH em resposta ao exercício em esteira, em ratos submetidos à fotoestimulação por laser de baixa intensidade $(780 \eta \mathrm{m})$ nos principais músculos da marcha.

\section{METODOLOGIA}

\section{Animais}

Este experimento foi aprovado pelo comitê de ética em pesquisa em animais da UFSCar e seguiu os princípios estabelecidos pelo American College of Sports Medicine. Fizeram parte do estudo, 54 ratos jovens (30 dias), Winstar, com peso inicial de $112 \pm 4,7 \mathrm{~g}$. Os animais foram acondicionados em gaiolas coletivas e receberam ração peletizada e água "ad libitum". Além disso, permaneceram em sala com temperatura controlada, na faixa de $22^{\circ}-27^{\circ} \mathrm{C}$, com fotoperíodo definido em 12 horas de claro e 12 horas de escuro.

\section{Procedimentos}

Os animais foram aleatoriamente divididos em quatro grupos: 1 - GRC (grupo repouso controle, $n=9$ ) e 2 - GRL (grupo repouso laser, $\mathrm{n}=10$ ), os quais permaneceram em repouso, sendo o segundo irradiado por laser. Os outros dois grupos, 3 - GEC (grupo exercício controle, n=16) e 4 - GEL (grupo exercício laser, $\mathrm{n}=19$ ), foram submetidos a um protocolo de treinamento aeróbio em esteira realizado 5 vezes por semana (domingo a quinta-feira) durante 5 semanas e a testes de esforço crescente descontínuo em esteira, uma vez por semana, totalizando 5 avaliações, no dia seguinte ao último dia de treinamento semanal (sexta-feira). Durante o teste foram coletadas amostras de sangue para verificar o LA dos animais. O último dia da semana (sábado) serviu de descanso para os animais.

\section{Instrumentação}

$\mathrm{O}$ treinamento aeróbio e o teste de esforço crescente foram realizados em uma esteira ergométrica para animais de pequeno porte, contendo três partes, cada qual com 7 raias individuais, o que permitiu que os animais se exercitassem 
simultaneamente e isoladamente. Para a dosagem do lactato sanguíneo foi utilizado um lactímetro eletroenzimático YSI MODEL 1500 Sport Lactate Analyzer. A irradiação foi realizada através de um equipamento laser na faixa espectral do infravermelho (GaAlAs), Classe IIIb-CEI-IEC 825-1 (MM Optics, São Carlos, Brasil).

\section{Adaptação, condicionamento do animal à esteira e treinamento aeróbio}

Todos os animais passaram, primeiramente, por um período de 6 dias consecutivos de adaptação e condicionamento à esteira, até atingirem, a partir da progressão da carga de trabalho (tempo de atividade e velocidade), um máximo de 10 minutos de esforço diário e velocidade de 17,5 (m/min) no $6^{\circ}$ dia que era o grau de esforço preconizado para a fase inicial do treinamento. A partir daí, iniciou-se o treinamento aeróbio o qual apresentava um aumento diário na carga de trabalho (2 minutos no tempo e uma progressão variável na velocidade), até se atingir uma meta pré-determinada para o último dia de treinamento semanal (Tabela 1). Esta graduação teve o intuito de possibilitar uma boa adaptação dos animais ao treinamento e favorecer um predomínio no treinamento aeróbio, conforme preconizado por Moraska et al. ${ }^{17}$. As sessões foram sempre no início do crepúsculo, período do dia em que os ratos naturalmente entram em sua mais alta atividade, por serem animais de hábito noturno.

\section{Teste de esforço e coleta de amostras de sangue}

O teste de esforço para a determinação do LA foi do tipo em degraus descontínuos com velocidades crescentes em esteira ergométrica. Antes do início do teste de esforço foi retirada a primeira amostra (linha de base). Em seguida, os animais foram submetidos a intervalos de esforço físico, com duração de três minutos, seguidos de intervalos de dois minutos a cada bloco de exercício para a coleta de sangue diretamente da cauda do animal por meio de um tubo capilar previamente calibrado e heparinizado. A velocidade da esteira aumentou em $4 \mathrm{~m} / \mathrm{min}$ a cada intervalo de exercício, com inclinação constante de $10 \%$, segundo teste realizado por Langfort et al. ${ }^{18}$ e Pilis et al. ${ }^{19}$, cuja velocidade inicial foi de $13 \mathrm{~m} / \mathrm{min}$, seguindo assim, até o momento da exaustão física. Depois, o sangue foi transferido para um tubo de capacidade de $0,5 \mathrm{ml}$ tipo "ependorff" contendo $50 \mu \mathrm{l}$ de anticoagulante (fluoreto de sódio). O material retirado foi mantido, durante o procedimento, refrigerado, sendo em seguida congelado em freezer até sua utilização na mensuração do lactato. Essa determinação do LA por meio da lactacidemia teve o propósito de caracterizar a predominância, no treinamento utilizado no estudo, do metabolismo aeróbio.

\section{Irradiação por laser de baixa intensidade}

A irradiação por laser foi realizada diariamente, utilizando como parâmetros: Comprimento de onda $780 \eta \mathrm{m}$, dose $=3,8$ $\mathrm{J} / \mathrm{cm}^{2}$, potência $=15 \mathrm{~mW}$, no modo contínuo, por 30 dias consecutivos, conforme recomendado por Halsberghe ${ }^{20}$. As aplicações foram realizadas imediatamente após a corrida na esteira, visando aproveitar as condições de "estresse físico" e conseqüentemente, de alterações metabólicas do animal, tendo em vista a maior eficácia do laser nessas condições ${ }^{2,21}$. As aplicações foram em número de quatro (quadríceps, TA, sóleo e glúteo máximo), bilateralmente, totalizando oito aplicações por animal/dia, todas sobre a pele depilada, utilizando-se a técnica pontual. A escolha dos pontos sobre a musculatura das patas traseiras e a quantidade de pontos teve o objetivo de obter uma resposta mensurável em proporções sistêmicas. A depilação foi um meio de minimizar a reflexão e a refração, e conseqüentemente, aumentar a efetividade do laser.

\section{Extração de tecidos, análise enzimática e eletroforese}

Nas análises enzimáticas foram utilizadas frações de músculo TA, sóleo e cardíaco retiradas 48 horas após a última sessão de exercício, com o intuito de garantir que eventuais modificações na atividade enzimática fossem decorrentes da aplicação do laser e não do efeito da última sessão de treinamento. A análise em músculo cardíaco visou identificar

Tabela 1. Valores médios ( \pm DP) das metas semanais das variáveis relacionadas ao programa de treinamento aeróbio.

\begin{tabular}{ccccc}
\hline SEMANAS & TEMPO & DISTÂNCIA & VEL. MÉDIA & VEL. MÉDIA \\
$\mathbf{N}^{\mathbf{0}}$ & $\mathbf{h}$ & $\mathbf{k m}$ & $\mathbf{k m} / \mathbf{h}$ & $\mathbf{m} / \mathbf{m i n}$ \\
\hline início & $0,16 \pm 0,03$ & $0,175 \pm 0,05$ & $1,09 \pm 0,26$ & $17,5 \pm 4,14$ \\
1 & $0,30 \pm 0,05$ & $0,393 \pm 0,09$ & $1,31 \pm 0,09$ & $21,0 \pm 1,46$ \\
2 & $0,50 \pm 0,05$ & $0,781 \pm 0,11$ & $1,56 \pm 0,08$ & $25,0 \pm 1,28$ \\
3 & $0,66 \pm 0,05$ & $1,134 \pm 0,11$ & $1,71 \pm 0,05$ & $27,5 \pm 0,76$ \\
4 & $0,83 \pm 0,05$ & $1,504 \pm 0,12$ & $1,81 \pm 0,03$ & $29,0 \pm 0,47$ \\
5 & $1,00 \pm 0,05$ & $1,906 \pm 0,13$ & $1,90 \pm 0,03$ & $30,5 \pm 0,47$ \\
\hline
\end{tabular}


possíveis efeitos sistêmicos do laser, tendo em vista que esse tecido não foi irradiado. As cinéticas enzimáticas foram realizadas por meio de espectrofotometria, cujos resultados foram expressos em UI/g de tecido ${ }^{-1}$ ( $\mu$ moles de substrato. $\mathrm{g}^{-1}$ de tecido fresco. $\mathrm{min}^{-1}$ ), a $25^{\circ} \mathrm{C}$. Já as eletroforeses foram realizadas em gel de amido e as quantificações das intensidades relativas das isoformas da $\mathrm{LDH}$ foram obtidas pelo método de diluições seriadas de Klebe ${ }^{22}$.

\section{Análise estatística}

Os resultados são apresentados através da média e desvio-padrão. Foram utilizados os testes: ANOVA para analisar a variância entre os grupos, no que se refere à atividade enzimática e padrão eletroforético, seguidos do post-hoc de Tukey. O LA de cada animal foi determinado por um examinador utilizando o modelo bi-segmentado no ponto de inflexão do teste de esforço crescente. O nível de significância foi considerado $(\mathrm{p} \leq 0,05)$.

\section{RESULTADOS}

\section{Atividade da LDH em 1 e 10 mM de substrato}

As atividades mais altas da LDH foram detectadas em extratos de músculo TA, seguindo-se das em músculo sóleo, e, as mais baixas no coração. Pode-se observar uma menor atividade de todos os grupos (4, 3 e 2) em relação ao controle (1) $(\mathrm{p}<0,01)$ para todos os tecidos. Foi possível ainda identificar uma semelhança no padrão de resposta nas duas concentrações estudadas, sendo que na menor concentração (1 mM) (Figura 1 a) o nível de atividade foi maior em relação à concentração maior $(10 \mathrm{mM})$ (Figura $1 \mathrm{~b})$.

\section{Razões B / A (atividade LDH em 1 mM / atividade em $10 \mathrm{mM}$ de piruvato)}

Observaram-se razões B / A maiores que 1 (Figura 2a) e, conseqüentemente, inibições em alta concentração de substrato $(10 \mathrm{mM})$ para todos os extratos teciduais, principalmente para o sóleo e coração (Figura 2b).

\section{Padrão eletroforético}

Houve um predomínio da subunidade B para o coração e sóleo, e um predomínio da subunidade A para o TA (Figura 3).

Foi possível ainda identificar aparente ação sistêmica do laser baseado na diminuição da LDH em músculo cardíaco por meio da comparação, principalmente, dos grupos submetidos ao exercício e laser e seu respectivo controle (grupo 3).

\section{DISCUSSÃO}

O laser de baixa intensidade constitui-se, atualmente, em uma das modalidades bioestimulantes mais utilizadas na reabilitação. No entanto, as evidências científicas e clínicas ainda são escassas e na maioria das vezes contraditórias, fato este que justifica a necessidade e importância da realização de pesquisas envolvendo esse recurso fisioterapêutico.

Assim, o presente estudo teve o propósito de investigar as possíveis adaptações bioquímicas relativas à atividade da enzima LDH, que ocupa posição chave no metabolismo glicolítico, e ao seu padrão eletroforético, em ratos submetidos a um treinamento aeróbio em esteira e a fotoestimulação por laser de baixa intensidade.

Primeiramente, relativo a atividade da $\mathrm{LDH}$, pode-se observar que todos os tecidos estudados (sóleo, TA e coração) apresentaram comportamentos semelhantes, no que se refere ao padrão de atividade entre os grupos, de modo que foi evidenciado uma menor atividade dessa enzima (maior inibição) de todos os grupos em relação ao grupo controle, sendo as menores atividades detectadas nos grupos submetidos ao laser associado ao exercício (grupo 4), ao exercício (grupo 3) e somente ao laser (grupo 2), respectivamente. Tal resposta era de se esperar, tendo em vista os estímulos propostos (exercício e/ou laser) visarem respostas aeróbias, em detrimento de respostas anaeróbias.

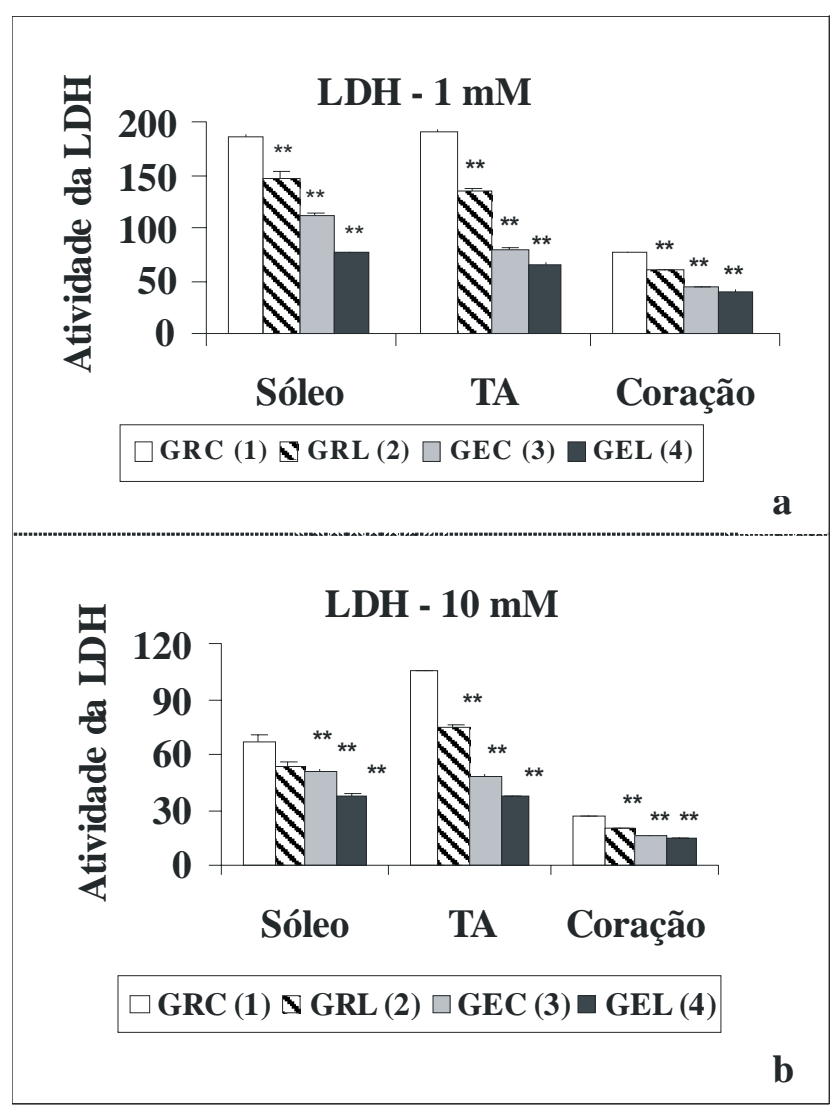

Figura 1. Atividade da Lactato Desidrogenase (LDH) em extratos de sóleo, TA e músculo cardíaco dos quarto grupos estudados, em $1 \mathrm{mM}$ (a) e $10 \mathrm{mM}$ (b) de piruvato. Valores são a média \pm desvio-padrão. Unidades são micromoles de substrato.minuto.g tecido ${ }^{-1} \cdot * *$ significância estatística $-\mathrm{p}<0.01$. 


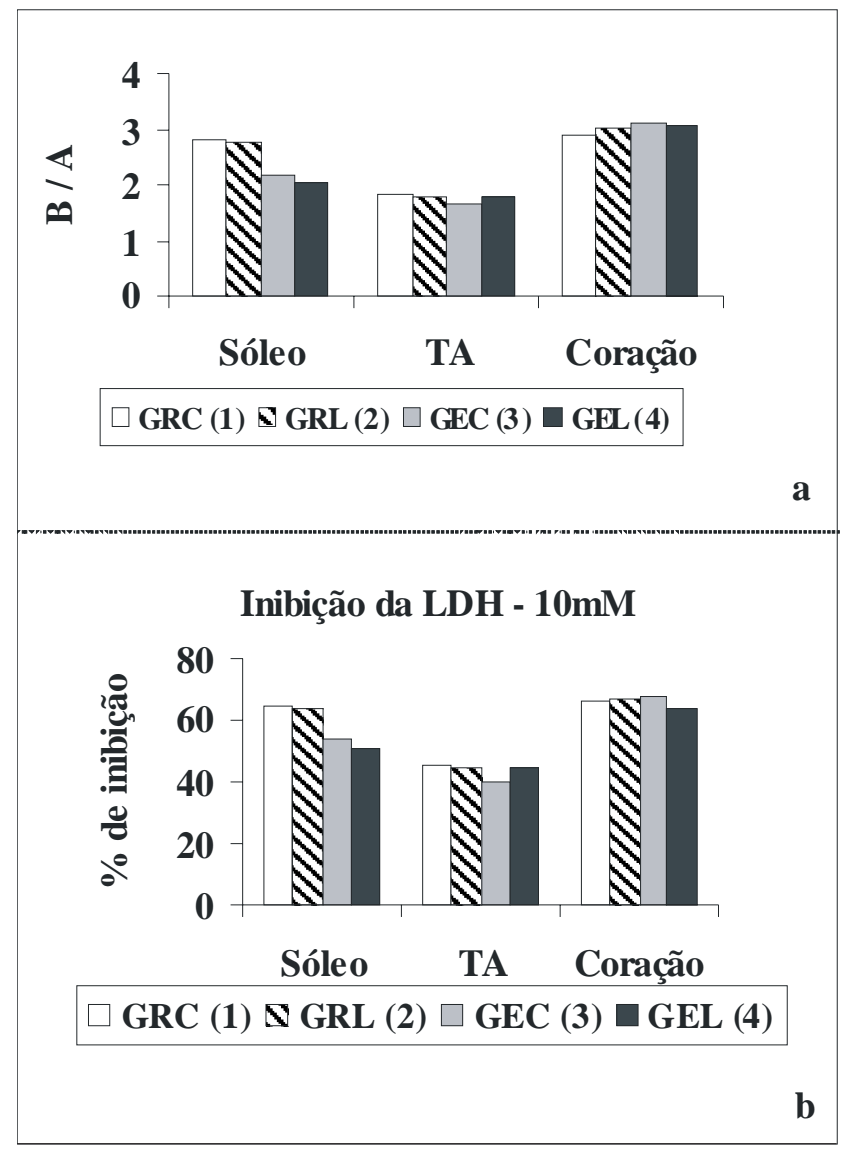

Figura 2. Razão B / A (a) e inibição da LDH em 10 mM de substrato (b) em extratos de sóleo, TA e músculo cardíaco dos quatro grupos estudados.

Autores $^{2,7,21,23}$ sugerem que a magnitude ou eficácia do efeito biomodulatório atribuído ao laser de baixa intensidade ao interagir com os tecidos biológicos, é dependente, dentre outros fatores, das condições metabólicas prévias do tecido, de tal forma que a resposta tende ser ótima quando o potencial redox celular se encontra alterado como, por exemplo, num quadro de lesão tecidual, cujo ambiente celular apresenta condições (diminuição do pH e do suprimento energético $\mathrm{O}_{2}$ ) que favorece a maior interação da radiação com os tecidos, e conseqüentemente, maior resposta biológica final (fotomodulação), diferentemente de quando o ambiente celular encontra-se em condições de normalidade fisiológica. Assim, considerando que a resposta foi maior no grupo submetido ao laser mediante exercício físico, provavelmente o "estresse metabólico" proporcionado pelo treinamento pode ter favorecido a maior ação do laser e conseqüentemente maior efetividade da resposta estimulatória do tecido.

Foi possível identificar também uma ligeira tendência do músculo TA em apresentar maiores valores de atividade em relação ao sóleo e coração. Isso parece estar relacionado com as características fisiológicas desse tecido (perfil metabólico), pois, considerando que o TA possui metabolismo predominantemente anaeróbio ${ }^{24}$ e a LDH é uma enzima chave desse tipo de metabolismo, já era de se esperar uma maior atividade nesse tecido.

O teste de esforço crescente para a determinação do LA pode também ser um fator que influencie diretamente o aumento na atividade da $\mathrm{LDH}$, sobretudo, em tecidos com características fisiológicas predominantemente anaeróbias. Corroborando tal hipótese, autores ${ }^{25}$, investigando a influência da duração e intensidade do exercício sobre adaptações bioquímicas do musculoesquelético, evidenciaram um maior estresse metabólico e, portanto, aumentada taxa glicolítica, durante as maiores velocidades de corrida, atribuindo tal
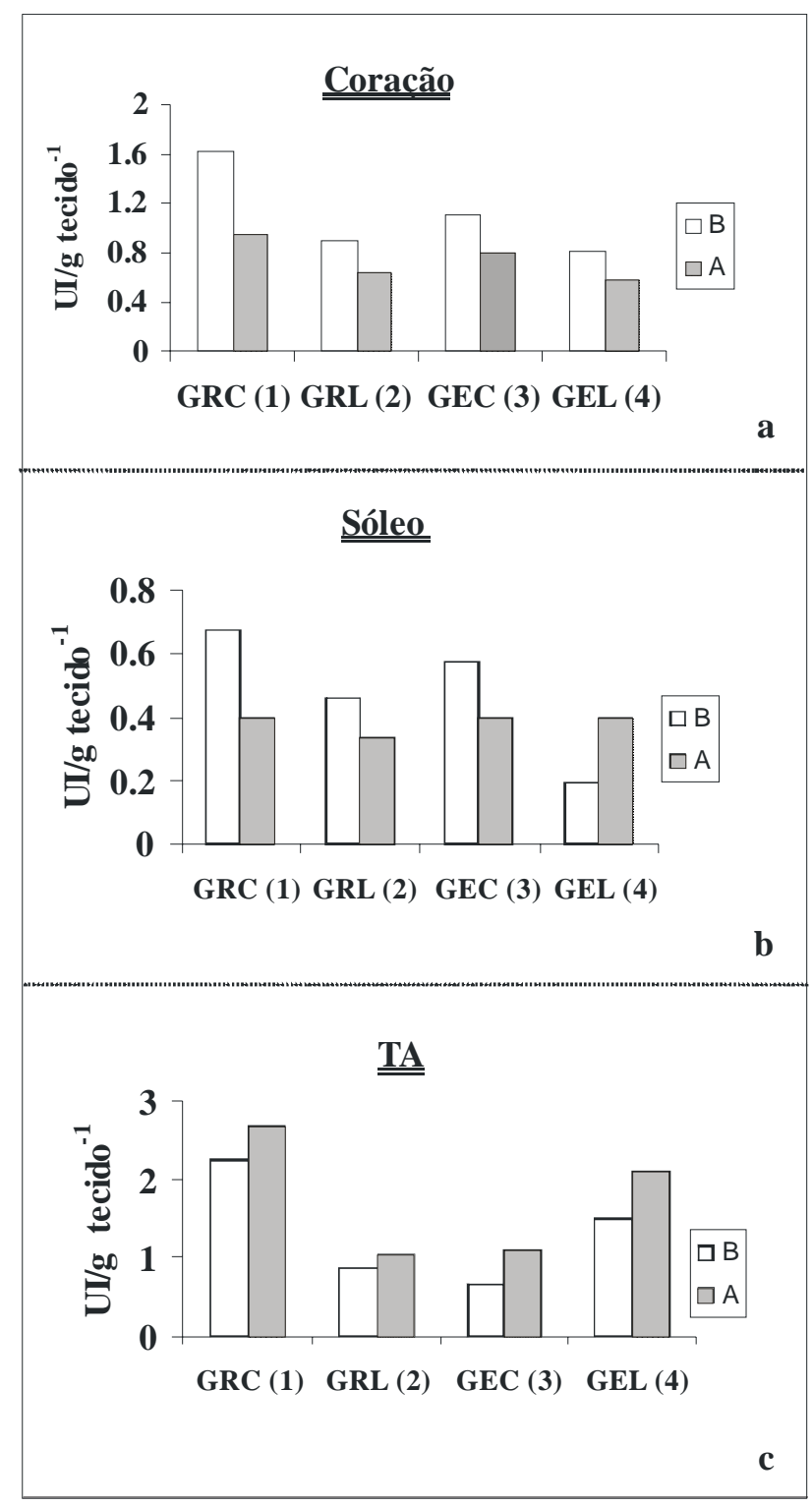

Figura 3. Padrão eletroforética da LDH, em extratos de sóleo, TA e músculo cardíaco dos quatro grupos estudados. Unidades são micromoles de substrato.minuto (UI). g tecido ${ }^{-1}$. 
achado ao maior número do contrações musculares requeridas, principalmente pelas fibras tipo IIb. Isso por sua vez, pode determinar o aumento na atividade de enzimas glicolíticas, como a LDH, principalmente em tecidos que apresentem uma predominância nesse tipo de fibra.

$A$ razão de atividade $\mathrm{B} / \mathrm{A}$ pode fornecer uma idéia do tipo de subunidade predominante em cada tecido, uma vez que a isoforma predominante em musculoesquelético de característica anaeróbia ( $\mathrm{A}_{4}-\mathrm{LDH}$ tipo muscular), possui pouca inibição em altas concentrações de substrato quando comparada à predominante em músculo cardíaco $\left(\mathrm{B}_{4}-\mathrm{LDH}\right.$ tipo cardíaco) que é fortemente inibida nessas concentrações. As relações obtidas no presente trabalho sugerem um predomínio da subunidade B nos 3 músculos analisados, tendo em vista terem se mostrado maiores que um, principalmente, para os músculos sóleo e cardíaco como era de se esperar, o que impediria o acúmulo de lactato nesses tecidos. Tal achado é corroborado tanto pelo maior percentual de inibição à concentração de $10 \mathrm{mM}$ de substrato $(51 \%$ a $65 \%$ em sóleo e $64 \%$ a $68 \%$ em coração), em relação ao TA cuja inibição variou entre (40\% a $45 \%$ ), bem como pelo predomínio da subunidade B, obtido através do método de diluições seriadas de Klebe ${ }^{22}$ nesses tecidos com características aeróbias. Por outro lado, o padrão eletroforético mostrou um predomínio da subunidade A para o músculo TA como já era de se esperar. No entanto, esse predomínio só ocorreu na forma de heteropolímero, e não na isoforma $\mathrm{A}_{4}$ como retrata a literatura científica. Assim, considerando a divergência de resposta entre a razão B / A e padrão eletroforético encontrada para o TA, bem como, a falta de um predomínio de homopolímeros $\mathrm{A}_{4}$ em músculo anaeróbio (TA), torna-se necessário ressaltar um provável padrão regulatório complexo para as isoformas da LDH devido a restrição de expressão do locus $L D H-A^{*}$ nessas espécies de animais (ratos).

Segundo Almeida-val ${ }^{26} \mathrm{o}$ aumento no produto do locus $L D H-A^{*}$ em determinado tecido pode estar relacionado a diferentes fatores, em destaque, o aumento da atividade glicolítica do tecido durante períodos de anaerobiose causada por uma diminuição da oferta de oxigênio no ambiente ou por um "estresse metabólico" decorrente de demandas energéticas maiores do organismo como no caso de um esforço intenso.

Portanto, os dados encontrados nesse estudo sugerem uma resposta adaptativa dos animais aos estímulos específicos do treinamento aeróbio e fotoestimulação por laser de baixa intensidade, no sentido da otimização da via oxidativa, verificada pela inibição da $\mathrm{LDH}$.

\section{REFERÊNCIAS BIBLIOGRÁFICAS}

1. Ortiz MCS, Carrinho PM, Santos AAS, Gonçalves RC, Parizotto NA. Laser de baixa intensidade: princípios e generalidades Parte 1. Fisioterapia Brasil 2001; 2: 221-40.

2. Karu TI. Photobiological fundaments of low power laser therapy. IEEE J Quant elect QE 1987; 23 (10): 1703-17.

3. Karu T, Pyatibrat L, Kalendo G. Irradiation with He-Ne laser increases ATP level in cells cultivated in vitro. J Photochem Photobiol B: Biol 1995; 27: 219-23.

4. Morimoto Y, Arai T, Kikuchi M, Nakajima S, Nakamura H. Effect of Low-intensity Argon Laser Irradiation on Mitochondrial Respiration. Lasers Surg Med 1994; 15: 191-9.

5. Passarella S, Ostuni A, Atlante A, Quagliariello E. Increase in the ADP/ATP exchange in rat liver mitochondria irradiated in vitro by helium-neon laser. Biochem Biophys Res Comm 1988; 156 (2): 978-86.

6. Passarella S, Casamassima E, Molinari S, Pastore D. Increase of proton eletrochemical potential and ATP synthesis in rat liver mitochondria irradiated in vitro by helium neon laser. FEBS 1984; 175 (1): 95-9.

7. Wilden L, Karthein R. Import of radiation phenomena of electrons and therapeutic low-level laser in regard to the mitochondrial energy transfer. J Clin Laser Med Surg 1998; 16 (3): 15965.

8. Yu W, Naim JO, Mcgowan M, Kippolito K, Lanzafame RJ. Photomodulation of Oxidative Metabolism and Electron Chain Enzymes in Rat Liver Mitochondria. Photochem Photobiol 1997; 66 (6): 866-71.

9. Manteifel V, Bakeeva L, Karu T. Ultrastructural changes in chondriome of human lymphocytes after irradiation with $\mathrm{He}$ Ne laser: appearance of giant mitochondria. J Photochem Photobiol B: Biol 1997; 38: 25-30.

10. Bakeeva LE, Manteifel VM, Rodichen EB, Karu T. Formation of giant mitochondria in human blood lymphocytes after HeNe laser. Mol Biol 1993; 27 (3): 608-17.

11. Pastore D, Di Martinho C, Bosco G, Passarella S. Stimulation of ATP synthesis via oxidative phosphorylation in wheat mitochondria irradiated with helium-neon laser. Biochem Mol Biol Int 1996; 39 (1): 149-57.

12. Quarto E, Martino G, Michelin IG, Covello C, Quartle IJ. Succinic oxydase activity in $\mathrm{He}-\mathrm{Ne}$ laser irradiated mitochondria. Boll Soc Int Biol Sper 1988; 64: 129-33.

13. Karu. Primary and secondary mechanisms of action of visible to near-IR radiation on cells. J Photochem Photobiol B: Biol 1999; 49: 1-17.

14. Apella E, Markert CL. Dissociation of lactate dehydrogenase into subunits with guanidine hydrochloride. Biochem Biophys Comm 1961; 6: 171-6.

15. Powers SK, Howley ET. Fisiologia do exercício: teoria e aplicação ao condicionamento e ao desempenho. 3 ed. São Paulo: Manole; 2000.

16. Wilmore JH, Costill DL. Fisiologia do esporte e do exercício. 2 ed. São Paulo: Manole; 2001. 
17. Moraska A, Deak T, Spencer RL, Roth D, Fleshner M. Treadmill running produces both positive and negative physiological adaptations in Sprague-Dawley rats. Am J Physiol Regulatory Integrative Comp Physiol 2000; 279: 1321-9.

18. Langfort J, Zarzeczny R, Pilis W, Kaciuba-Uscieko H, Nazar K, Porta S, et al. Effect of Sustained Hyperadrenalinemia on Exercise Performance and Lactate Threshold in Rats. Comp Biochem Physiol 1996; 114a (1): 51-5.

19. Pilis W, Zarzeczny R, Langfort J, Kaciuba-Uscieko H, Nazar K, Wojtyna J. Anaerobic Threshold in Rats. Comp Biochem Physiol 1993; 106A (2): 285-9.

20. Halsberghe MJE. Estudo de Indicadores de Taxas de Metabolismo Aeróbio e Anaeróbio em Musculatura de Ratos em Resposta à Irradiação com Laser em Baixa Intensidade [Monografia]. São Carlos (SP): UFSCar; 2003.

21. Kitchen SS, Partridge CJ. A review of level laser therapy. Part I: background, physiological effects and hazards. Physiotherapy 1991; 77 (3): 161-70.
22. Klebe RJ. A simple method for the quantitaion of isozyme patterns. Biochem Gen 1975; 11/12: 805-12.

23. Beckerman H, De Bie R, Bouter L, Cuyper H, Oostendorp R. The efficacy of laser therapy for musculoskeletal and skin disorders: A criteria-based meta-analysis of randomized clinical trials. Physical Therapy 1992; 72: 483-91.

24. Lieber RL. Skeletal Muscle Structure and Function. Implications for Rehabilitation and Sportes Medicine. Maryland: Williams \& Wilkins; 1992.

25. Dudley GA, Abraham WM, Terjung RL. Influence of exercise intensity and duration on biochemical adaptations in skeletal muscle. J Appl Physiol 1982; 53 (4): 844-50.

26. Almeida-Val VMF, Farias LP, Paula-Silva MN, Duncam WP. Biochemical adjustments to hypoxia in amazon cichlids. Braz $\mathrm{J}$ Med Biochem Res 1995; 28: 1257-63. 